\title{
The Modeling of Drying Process of a Grain Moving Layer with Inversion
}

\author{
Sergey Alexandrovich Podgorny ${ }^{1}$, Vyacheslav Stepanovich Kosachev ${ }^{1}$, Eugene Panteleyevich Koshevoy ${ }^{1}$, \\ Anzaur Adamovich Skhalyakhov ${ }^{2} \&$ Hazret Ruslanovich Siyukhov $^{2}$ \\ ${ }^{1}$ Kuban state technological university, Krasnodar, The Russian Federation \\ ${ }^{2}$ Maikop state technological university, Maikop, The Republic of Adygea \\ Correspondence: Sergey Alexandrovich Podgorny, Kuban state technological university, Krasnodar 350072, The \\ Russian Federation. E-mail: arama75@mail.ru
}

Received: October 30, $2014 \quad$ Accepted: November 7, $2014 \quad$ Online Published: January 11, 2015

doi:10.5539/mas.v9n4p126 URL: http://dx.doi.org/10.5539/mas.v9n4p126

\begin{abstract}
The process of drying in a moving grain layer with cross ingrained production line of a siccative agent is applied in some constructions of dryers. To determine the effectiveness of inversion the modeling of the drying process was developed, which is based on dependences describing the drying process in the layer. The description of the drying process in the potentials of mass transfer which allowed considering the changing profiles of moisture content and temperature interactive streams of a grain and a grain drying agent was proposed. The efficiency of inversion during the process of drying is achieved. When modeling two - and three-segment organization of drying process of a grain moving layer with inversion (direction alternation) interacting flows of grain and drying agent, it is established that on the second segment in both cases allows reducing the unevenness of the dried-up grain, leaving the dryer.
\end{abstract}

Keywords: drying, cross contact of phases, inversion, differential equations, potentials of mass carry

\section{Introduction}

\subsection{The Analysis of the Structure and Modes of Inversion of the Grain Moving Layer}

In applied and developed grain drying apparatus (De Farias R. P. et al., 2004; Podgorny S.A. et al., 2014) the drying process in a moving layer is realized. It interacts with the cross-flow drying agent. The flows inversion in the dryer can be effective (Babalis S.J. et al., 2005). For reasoning the structure and modes of inversion of the grain moving layer it should be modeling the process of drying with the assessment of the distribution profiles of potential mass carry (Podgornaya S.A., et al., 2012) in interacting flows.

In the present case, the modeling process with the potentials of mass carry in a moving layer with cross-flow drying agent can be simplified on the basis of dependency similarly to the heat exchange between intersecting streams (Hausen H., 1976; Anzelius, A., 1926; Hoffman A., 2000; Kosachev V.S. et al., 2008) when using the potential of transportation. In this case, the differential system of heat and moisture equations in a grain is converted into one generalized differential equation of transfer capacity (Maroulis, Z. B. et al., 1995; Qi, J.S. et al., 1996; Parry, J. L., 1985). From this point of view the established process of drying of a grain layer can be represented as the process of potential migration in a two-dimensional orthogonal coordinate system: the height of the layer of material and goods movement on the dryer (Chemkhi S. et al., 2004; Chemkhi S. et al., 2002; Tarek J. J et al., 2010)

\section{Materials and Methods}

\subsection{Modeling of the Drying Process to Determine the Effectiveness of Inversion Layer Moving Grain}

In the concerned process (Figure 1), the original drying agent with the potential decrease in the vertical direction Y flows evenly distributed through the layer of a dried material moving from left to right, and all of the settings related to the drying agent, have the index "1". For $x=0 \Theta_{1}=\Theta_{10}$, which means that the input capacity of the drying agent $1, \Theta_{10}$, for all values of $\mathrm{x}$ is constant. Source drying material with increased capacity in the horizontal x-direction flows evenly distributed from left to right, and all values are index "2". For $x=0 \Theta_{2}=$ $\Theta_{20}$, which means that the input potential material $2, \Theta_{20}$, for all values of y constant. 
The initial dryable material with the potential extension in a horizontal $\mathrm{x}$-direction flow evenly dispersed from the left to the right and all values have the same index "2". For $x=0 \Theta_{2}=\Theta_{20}$ that means that the entrance potential of a material $2, \Theta_{20}$, for all values y is constant.

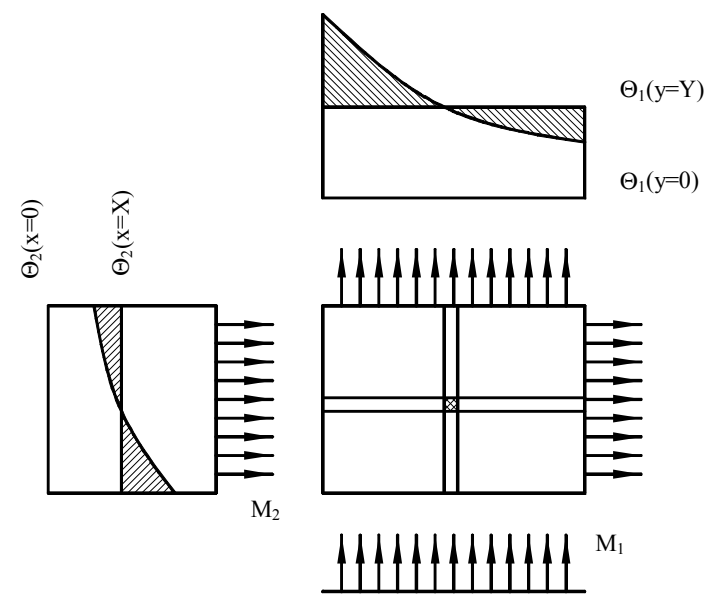

Figure 1. The denotations for scheme analysis of potential transportation in the dryer with cross - cut stream flow of the dryable material and the drying agent penetrating it

Considering that potential represents conditional size, and is defined rather reference size, we will consider change of excess potential from its conditional zero value. In this case the potential of the drying agent 1 changes from $\mathrm{y}=0$ to $\mathrm{Y}$, and a material 2 layer from $\mathrm{x}=0$ to $\mathrm{X}$.

The mass flows of the drying agent $(\mathrm{kg} / \mathrm{s})$ and drying product $(\mathrm{kg} / \mathrm{s})$ in conditions of the established mode of drying are considered permanent.

To set the balance of potentials we use a similar approach to the heat balance. Considering the path of the drying agent (dy) and the dryable material (dx), which cross each other on an elementary area (dx $\times d y)$. In this section, it is occurred the potential transportation between the drying agent and dryable material through the cross-cut area of the element. The mass elementary flow of the drying agent 1, taking into account a mass capacity $\dot{M}_{1} \cdot C_{m 1} \cdot(d y / Y)$, changes the potential at a speed $\left(\partial \Theta_{1} / \partial \mathrm{x}\right) \times \mathrm{dx}$, at the same time the elementary stream of the dryable material 2, taking into account a mass capacity $\dot{M}_{2} \cdot C_{m 2} \cdot(d x / X)$, changes the potential at a speed $\left(\partial \Theta_{2} / \partial y\right) \times d y$.

The description of the process is possible on the basis of obtaining similar dependences of potential exchange between intersecting streams (Kosachev V.S et al., 1976)

in the drying agent:

$$
\Theta_{1}(a, b)=1-\int_{0}^{a^{*}} e^{-(a+b)} \cdot \sum_{N=0}^{\infty} \frac{(a \cdot b)^{N}}{(N !)^{2}} \partial a
$$

in the dried material:

$$
\Theta_{2}(a, b)=\int_{0}^{b^{*}} e^{-(a+b)} \cdot \sum_{N=0}^{\infty} \frac{(a \cdot b)^{N}}{(N !)^{2}} \partial b
$$

As a result of integrating by parts of equations (1) and (2) the following expressions for the local non-dimensional potentials are obtained:

In the drying agent:

$$
\Theta_{1}(a, b . N)=1-\exp (-b) \cdot \sum_{i=0}^{N} \frac{b^{i}}{i !}+\exp (-a-b) \cdot \sum_{m=0}^{N}\left(\frac{b^{m}}{m !} \cdot \sum_{i=0}^{m} \frac{a^{i}}{i !}\right)
$$

in the dried material:

$$
\Theta_{2}(a, b . N)=\exp (-a) \cdot \sum_{i=0}^{N} \frac{a^{i}}{i !}-\exp (-a-b) \cdot \sum_{m=0}^{N}\left(\frac{a^{m}}{m !} \cdot \sum_{i=0}^{m} \frac{b^{i}}{i !}\right)
$$

The received ranks quickly meet and give the sufficient accuracy of the decision at $6 \ldots 7$ members. They can be 
used for calculating the potential fields of dryers.

For modeling the drying at multi-graded phase contact change it is necessary to find the solution at the initial uneven distribution of potentials. The problem was solved numerically, for this purpose the initial differential equations are presented in final differences (Kosachev V.S. et al., 2010). At initial evenly distribution of potentials the analytical decision was used as a reference for the numerical decision.

For identification the parameters of grain drying process the experimental data obtained by drying a layer of wheat were used (Mironov, N.A. et al., 2010).

The kinetics of drying of a grain layer was studied at constant process parameters: temperature, velocity and humidity of the drying agent.

Using the expression for the relative potentials of the drying agent and the drying material layer (3) and (4), and also the dependences for determining the grain potentials:

$$
\Theta(u)=575,566 \cdot \exp (-16,1627 \cdot u), \frac{\text { Дж }}{\kappa 2}
$$

and a drying agent:

$$
\theta_{v v}=\frac{\left(R_{s v}+x R_{p}\right) x P T}{(1+x)(0,622+x) P_{s}}
$$

The received dependences between potentials and moisture content, allowed defining the mass values, using the equations respectively for grain (5) and moist air.

The generalized curve of kinetics of a wheat grain layer drying through potentials according to the data of experiences depending on parameter $\mathrm{b}$ is presented by the following equation:

$$
K_{\Theta}=-0,3384 \cdot b^{2}+0,9551 \cdot b
$$

The processing of experimental data has shown that the parameter $b$ is linearly related to the drying time of the material.

As a result of the dispersive analysis it was established that statistically significant factors are the temperature (Tr) and the air speed ( $\mathrm{Vr})$. At the same time adequate equation describing $\mathrm{Kb}$, is:

$$
K_{b}=-0,15345+0,00041 \cdot T_{r}+0,00052 \cdot V_{r}
$$

2.2 The Description of the Drying Process Allowing Considering the Changing Profiles of Moisture Content and Temperature Interactive Streams of a Grain and a Grain Drying Agent

When modeling with the use of numerical methods of final differences, the sequence of segments was considered, which differed the direction of the drying agent flows (Babalis S.J. et al., 2005; Tarek J. J. et al., 2010; Albaraka Z. et al., 2008; Davidson et al., 1999).

Figure 2 shows the versions of the two-segment scheme.

Fundamentally there are two possible variants: A - without inversion and B - with inversion. The modeling results are presented in Table 1.

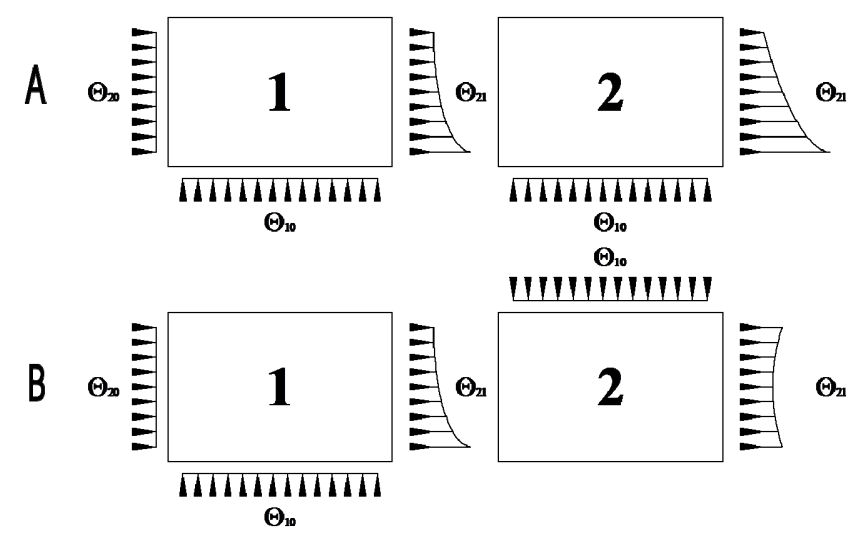

Figure 2. Variants of two-segment scheme 
Table 1. Statistical characteristics of a potential flow of a dried-up material in the two-segment scheme (without rotation and with rotation)

\begin{tabular}{lcc}
\multicolumn{1}{c}{ Parameters } & $\begin{array}{c}\text { Without } \\
\text { rotation }\end{array}$ & With rotation \\
\hline The average potential on the first segment & 0,263 & 0,263 \\
The average potential at the exit from the first segment & 0,478 & 0,478 \\
The average potential on the second segment & 0,619 & 0,627 \\
The minimum potential on the second segment & 0,347 & 0,347 \\
The maximum potential on the second segment & 0,865 & 0,762 \\
Average potential at the exit from the second segment & 0,733 & 0,753 \\
The minimum potential at the exit on the second segment & 0,589 & 0,750 \\
The maximum potential at the exit on the second segment & 0,865 & 0,762 \\
\hline
\end{tabular}

Apparently from the presented data (Table 1) the potential transmission efficiency at a change of the direction of a potential flow of the drying agent on the second segment increases in comparison with the constant direction of this potential flow.

Thus, the use of two-segment model allows, if supporting the identical uniformity of drying, reducing the effective length of a potential contact on this axis.

We'll consider the variants of the three-segment scheme (Figure 3).

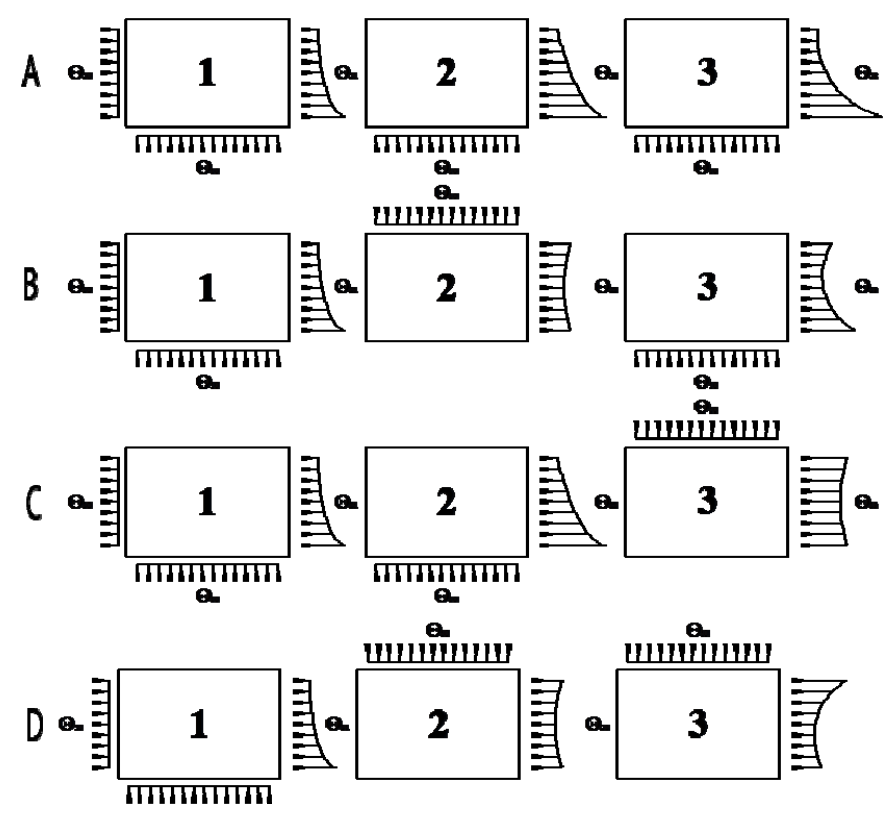

Figure 3. Versions of the three-segment scheme

In the variant A there's no inversion, it may be accepted as the basic and be calculated on the analytical dependences.

Table 2. Statistical characteristics of a potential flow of a dried-up material without change of the direction and at a change of the direction of a potential flow of the drying agent on the second segment on 180 degrees in the three-segment scheme

\begin{tabular}{lcc}
\hline \multicolumn{1}{c}{ Parameters } & $\begin{array}{l}\text { Without } \\
\text { rotation }\end{array}$ & With rotation \\
\hline The average potential on the first segment & 0,151 & 0,151 \\
The average potential at the exit from the first segment & 0,288 & 0,288 \\
\hline
\end{tabular}




\begin{tabular}{lcc}
\multicolumn{1}{c}{ Parameters } & $\begin{array}{c}\text { Without } \\
\text { rotation }\end{array}$ & With rotation \\
\hline The average potential on the second segment & 0,398 & 0,403 \\
The minimum potential on the second segment & 0,191 & 0,191 \\
The maximum potential on the second segment & 0,652 & 0,521 \\
Average potential at the exit from the second segment & 0,498 & 0,510 \\
The minimum potential at the exit on the second segment & 0,346 & 0,505 \\
The maximum potential at the exit on the second segment & 0,652 & 0,521 \\
\hline
\end{tabular}

Apparently from the presented data (Table 2) the efficiency of a potential transfer when changing the direction of a potential flow of the drying agent on the second segment (option B) increases in comparison with the constant direction of this potential flow. Options $\mathrm{C}$ and $\mathrm{D}$ are kinds of the two-segment scheme. The indicators of options $\mathrm{B}$ and $\mathrm{D}$ are close on uniformity of drying (Figure 4), but by option $\mathrm{D}$ there are less inversions and respectively it is simpler.

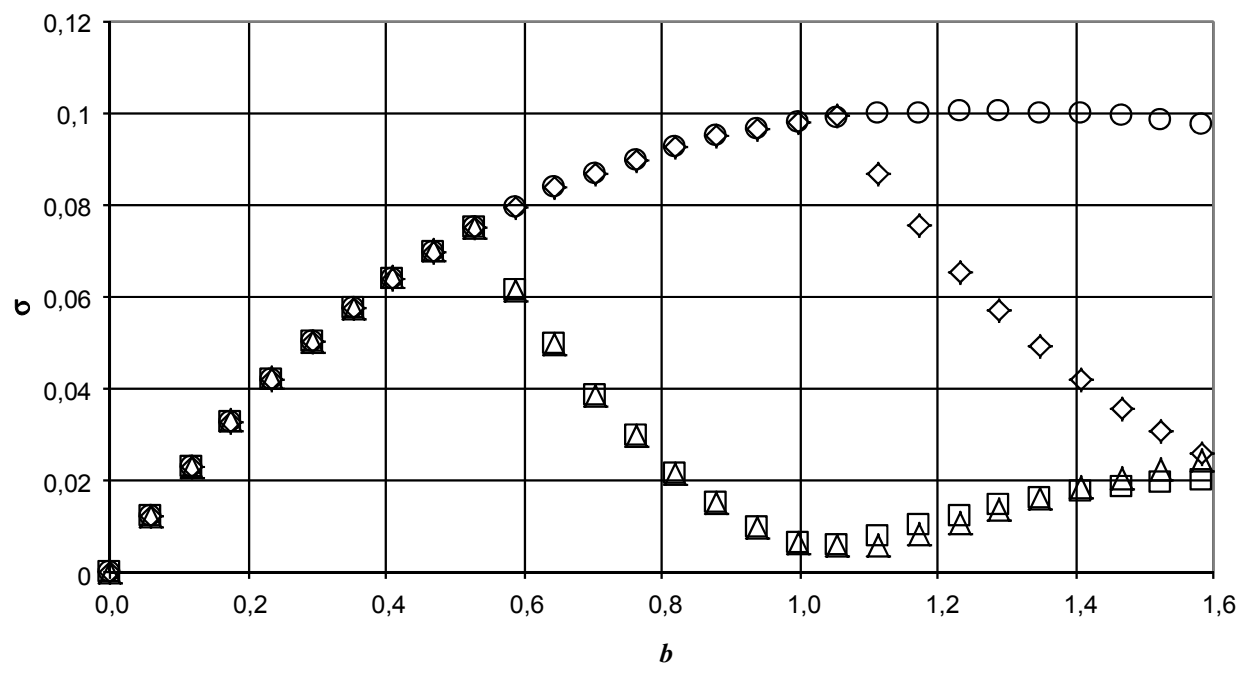

$O A \Delta B \diamond B \square \Gamma$

Figure 4. The standard deviation of the profile field potentials of the stream dried grain $\Theta_{2}$ in a three-segment scheme

The given theoretical analysis showed that the use of inversion, i.e. the periodically change of the direction of moving grain layer blowing, will ensure uniform drying without reducing the thickness and temperature of the drying agent, and will have high efficiency and low specific energy consumption.

The scheme of flows of the drying agent in the dryer is shown in Figure 5. By placing the internal cruciform dividers the distribution camera is divided into four zones, two are located aflat taking away a flow of the drying agent passed through moving layers of grain from external collectors, and the other two are located vertically bringing the initial drying agent from furnace - ventilating units. Horizontally located taking-away cameras from the furnace - ventilating units are muffled, and from the opposite side are open. Vertically located bringing cameras on the contrary, from the furnace - ventilating units are open, and from the opposite side are closed. 


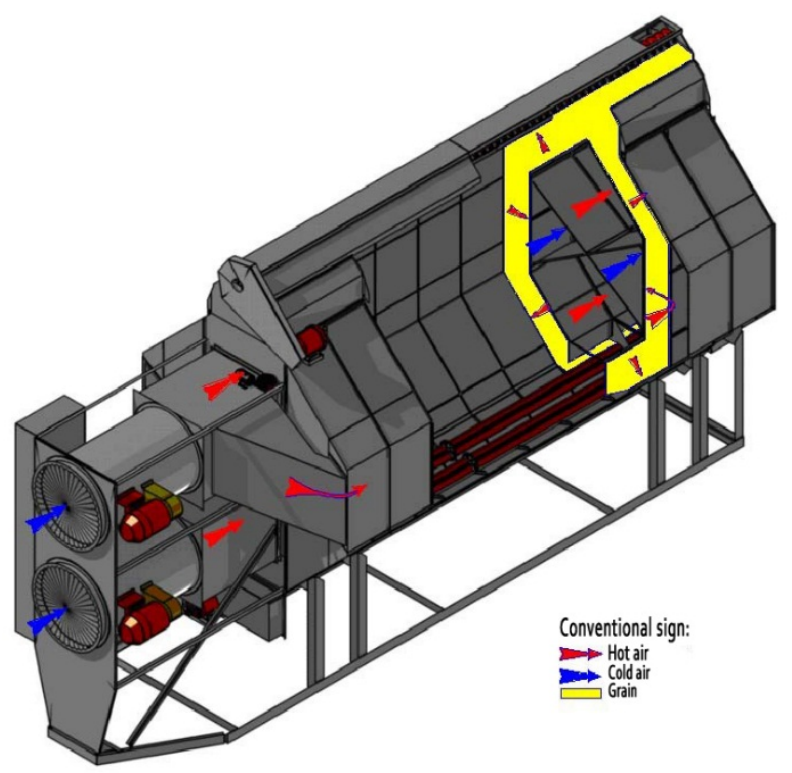

Figure 5. The scheme of movement of the inverted flows of the drying agent in a grain dryer

As a result, the channels of the symmetrical bifurcated flow of grain, created between the outer and inner perforated walls, divided into three sections - the inclined upper, middle and lower sloping vertical. Accordingly, these three sites purged drying agent - in the direction of the top of the inner zone of the feed to the outside; middle - in the direction of the external reservoir in the internal abductor zone; lower - in the direction of the feed zone to the outside. Due to such established system of alternation of flows direction, the uniformity and intensity increase of drying grain is provided.

For a two-module dryers, to overcome the above drawbacks it is proposed to install a single inverter (grain flow).

In this case the zone of motion of a symmetrical bifurcated grain flow is divided into five sections - the upper sloping, the middle vertical, and the inverting area, the lower vertical and lower sloping.

The dryer has an inverter that is installed between the working chambers adjacent the flow path of the grain of one of the channels in the same channel on the opposite side. At the same time the sides of a grain layer before passing through the inverter changing the places against the flow direction of the drying agent. Internal cameras are formed by a horizontal partition of the general internal rhomboid space. Vertically two chambers - the upper and lower - are connected to the furnace - ventilating units, which they injected the original drying agent. From the opposite side the both cameras are closed by a solid partition. Therefore, the flow of drying agent permeates the perforated inner wall of successively moving grain layer, the perforated outer wall and then leaves the space surrounding the dryer.

There are two variants of the inverter. The first version is the non- driving line inverter (Figure 5) and the second version is the driving inverter (Figure 6).

Non- driving inverter (Figure 5) represents the systems of channels of the device facilitating the flow of fluids located opposite to each other.

Each of the devices facilitating the flow of fluids in a two-modular grain dryer has a receiving apparatus and the receiver for flow collecting and sending them to the bottom module of the dryer unit. The inverter is located at the intersection of flows in the zone.

As shown in Figure 5, the devices facilitating the flow of fluids are casing to each other so that the dissectors alternate with each other.

Such performance of the dryer provides the movement of a grain material adjacent to an internal wall, above the lying working camera of the dryer to external walls underlying, and from external walls overlying to internal underlying that increases uniformity of drying.

Accordingly, these portions are blown by a flow of drying agent in the direction of the inside of the distribution 
chamber to the outside. Due to such a scheme of motion of the grain flow the intensity and uniformity of drying grain is provided.

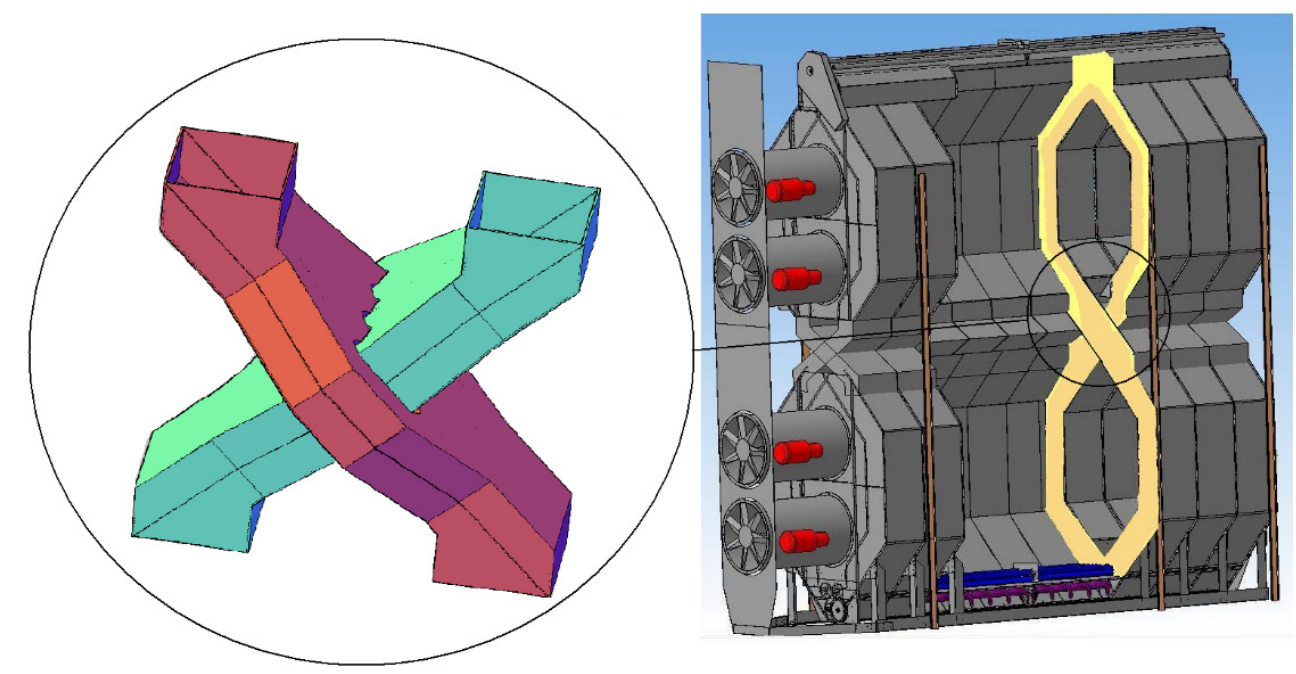

Figure 5. The scheme of movement of grain in a two-modular dryer, non-inverting (grain flow)

For a two-module dryers inverted (grain flow), it is possible the use of the driving inverter (Figure 6).

The inverter includes two porTable troughs located opposite each other on the intersection of which there is a cylindrical tube with holes on the sides and edges to distribute the movement of grain layers. The branch pipe set in motion by the driving gear with a pace servo-engine. It is possible to use hydro or pneumocylinders with a control system.

In general, the developed technical proposals allow to realize the drying process with inversion, which provides uniformity and intensity of a drying grain.

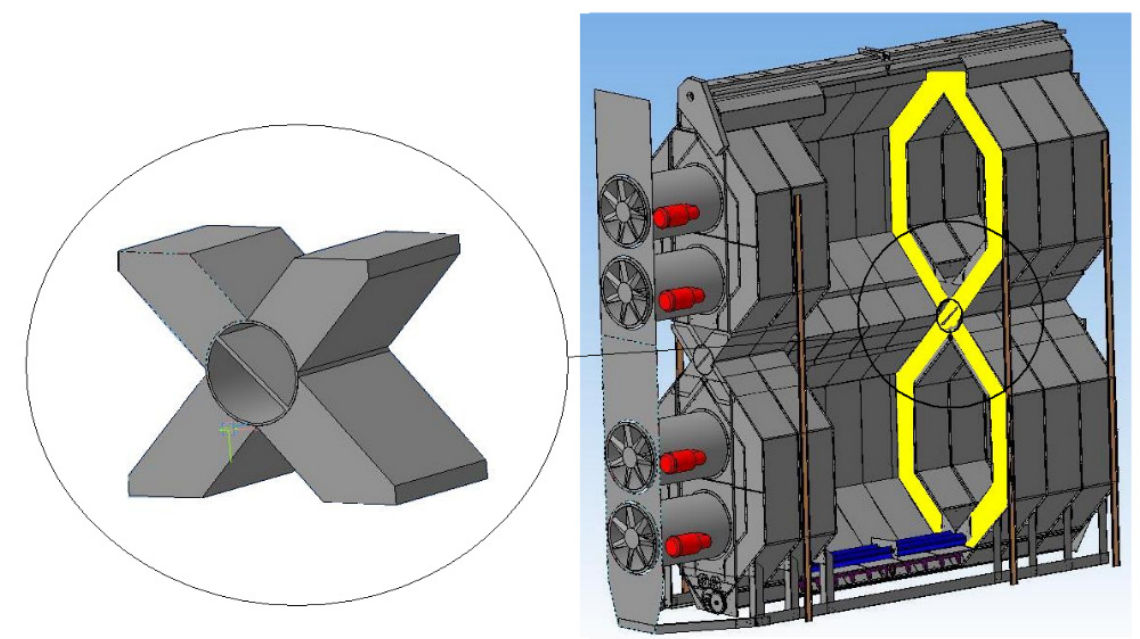

Figure 6. The scheme of grain movement in a two-module dryer by inverting (grain flow)

Thus, the intensification of the process and increase of the uniformity of drying is possible with the use of inversion - changing the direction of interactive flow of grain drying and drying agent.

\section{Results and Discussion}

The process of drying of a moving grain layer with inversion application, i.e. periodical change of the expulsion direction, increases the uniformity of drying, without reducing thickness of a layer and temperature of the drying agent that gives the high quality and drying productivity.

At initial uniform distribution of potentials when drying a grain moving layer blown by a cross flow of the 
drying agent, the description of process is possible on the basis of analytical dependence. When drying a grain layer with the initial uneven distribution of potentials on height, the numerical decision is received by a method of final differences.

The experimental data on the kinetics of drying the wheat layer with high accuracy generalized the dependences for relatively average height of the potential layer from parameter $b$.

The drying process with the use of inversion is possible in two ways: the stream dried material does not change its direction of movement, and the flow of the drying agent changes or the flow of the drying agent does not change its direction of movement, as the stream of the dried material changes. For realization of these ways two designs of dryers are offered.

\section{Concluding Remarks}

When modeling two - and three-segment organization of drying process of a grain moving layer with inversion (direction alternation) interacting flows of grain and drying agent, it is established that on the second segment in both cases allows reducing the unevenness of the dried-up grain, leaving the dryer.

\section{Acknowledgements}

The authors appreciate Kuban state technological university, Maikop state technological university.

\section{References}

Albaraka, Z., Trebouet, D., Tuna, M., Loureiro, J. M., \& Burgard, M. (2008). SFGP 2007 - An Analysis of the Mass Transfer in a Non-Dispersive Solvent Extraction Closed System. Int. J. of Chem. Reactor Eng, 6, A13.

Anzelius, A. (1926). Uber Erwarmung using durchstromender Medien. (band 6, heft 4, p. 291). Z. f. angew. Math. u. Mech.

Babalis, S. J., Papanicolaou, E., \& Belessiotis, V. G. (2005). Impact of alternating drying-air flow direction on the drying kinetics of agricultural products (pp. 300-305). Proceedings of the 3rd IASME/WSEAS Int. Conf. on HEAT TRANSFER, THERMAL ENGINEERING AND ENVIRONMENT, Corfu, Greece.

Babalis, S. J., Papanicolaou, E., \& Belessiotis, V. G. (2005). Impact of alternating drying-air flow direction on the drying kinetics of agricultural products (pp. 300-305). Proceedings of the 3rd IASME/WSEAS Int. Conf. on HEAT TRANSFER, THERMAL ENGINEERING AND ENVIRONMENT, Corfu, Greece.

Chemkhi, S., Mihoubi, D., Zagrouba, F., \& Bellagi, A. (2002). Experimental and thermodynamic analyses of sorption isotherms of food products. $15^{\text {th }}$ International Congress of Chemical and Process Engineering, Praha, Czech Republic.

Chemkhi, S., Zagrouba, F., \& Bellagi, A. (2004). Thermodynamic Study of Moisture Sorption. Desorption in Clay. $16^{\text {th }}$ International Congress of Chemical and Process Engineering. Prague, Czech Republic.

Davidson, J., Oberreit, D., Liu, W., \& Mantell, S. (1999). Are plastic heat exchangers feasible for solar water heaters? Part I: A review of the technology, codes and standards and commercial products. Proceedings: Renewable and Advanced Energy Systems for the $21^{\text {st }}$ Century, Maui, HI.

De Farias, R. P., Santiago, D. C., de Holanda, P. R. H., \& de Lima, A. G. B. (2004). Drying of grains in conveyor dryer and cross flow: A numerical solution using finite-volume method. Revista Brasileira de Produtos Agroindustriais, 6(1), 1-16. Samra Grande.

Dural, N. H., \& Hines, A. L. (1992). Diffusion of water in cereal-bread type food fibers. J. Process Engng, 15, 115. http://dx.doi.org/10.1111/j.1745-4530.1992.tb00146.x

Efremov, G., \& Kudra, T. (2004). Calculation of the effective diffusion coefficients by applying a quasi-stationary equation for drying kinetics. Drying Technology: An International Journal, 22(10), 2004. http://dx.doi.org/10.1081/DRT-200039993

Hausen, H. (1976). Warmeubertragung im Gegenstrom, Gleichstrom und Kreuzstrom. 2. Aufl. Springer-Verlag, Berlin, Heidelberg, New York.

Hoffman, A. (2000). Theoretical solution for the cross-flow heat exchanger. Heat and Mass Transfer, 36, 127-133. http://dx.doi.org/10.1007/s002310050374

Karathanos, V. T., Villalobos, G., \& Saravacos, G. D. (1990). Comparison of two methods of estimation of the effective moisture diffusivity from drying data. J. Food Sci., 55(1), 218-223. http://dx.doi.org/10.1111/j.1365-2621.1990.tb06056.x 
Kosachev, V. S., Koshevoy, H. E., \& Mikhnevich, A. N. (2008). Mironov Nasaviisasta for the description of heat transfer in a layer. Izvestiya vuzov "Food technology", 2-3, 80-82.

Kosachev, V. S., Koshevoy, H. E., Mikhnevich, A. N., \& Mironov, N. A. (2009). Numerical solution of the problem of heat transfer in cross the contact of phases. Izvestiya vuzov "Food technology", 2-3.

Maroulis, Z. B., Kiranoudis, C. T., \& Marionos, K. D. (1995). Heat and mass transfer modeling in air drying of foods. Journal of Food Engineering, 26, 113-130. http://dx.doi.org/10.1016/0260-8774(94)00040-G

Mironov, N. A., Podgornaya, S. A., Kosachev, V. S., \& Koshevoy, H. E. (2010). Identification of parameters of drying of grain in the layer through the potential of mass transfer. New technologies, 2, 63-68.

Parry, J. L. (1985). Mathematical modelling and computer simulation of heat and mass transfer in agricultural grain drying. A review. Journal of Agricultural Engineering Research, 32, 1-29. http://dx.doi.org/10.1016/0021-8634(85)90116-7

Podgornaya, S. A., Koshevoy, H. E., \& Kosachev, V. S. (2012). Mathematical modeling of the processes of drying and conditioning of grain. Potentials of mass transfer. LAMBERT Academic. Publishing.

Podgorny, S. A., Koshevoy, H. E., Ghukasyan, A. V., \& Kosachev, V. S. (2014). Installation for drying and vacuum cooling grain (pp. 35-38). Modern problems of technique and technology of food production. Materials of the XV international scientific-practical conference. Barnaul, Publishing house AltGTU.

Qi, J. S., \& Krishnan, C. (1996). Matematical modeling of continuous cross-flow diffusion-controlled dryers. Chemical Engineering Science, 51(21), 4769-4780. http://dx.doi.org/10.1016/0009-2509(96)00332-6

Tarek, J. J., \& Madhumita, B. R. (2010). Application of Computational Fluid Dynamics for Simulation of Drying Processes: A Review. Drying Technology, 28, 120-154.

\section{Copyrights}

Copyright for this article is retained by the author(s), with first publication rights granted to the journal.

This is an open-access article distributed under the terms and conditions of the Creative Commons Attribution license (http://creativecommons.org/licenses/by/3.0/). 